\title{
Long-Term Outcome of Orthognathic Surgery
}

\author{
Lisen Espeland and Arild Stenvik \\ University of Oslo \\ Norway
}

\section{Introduction}

Orthognathic surgery is treatment which often leads to great improvement in function and appearance, but is demanding to the patient, considerable resources are being spent, and risks for unwanted side effects are involved. Because of the elective nature of the treatment it is particularly important that the patient is well informed about all aspects of the provision and outcome of treatment before the decision to initiate treatment is reached. This information should be evidence-based. In this area it is, however, difficult to establish research materials that are both homogenous and of adequate size. The present chapter represents an attempt to summarize research findings from long-term follow-up of more than 1000 patients treated according to an established protocol over a period of 15 years.

\section{Background}

Since 1970 an orthognathic team of orthodontists and maxillofacial surgeons at the University of Oslo has monitored patients referred for advice and treatment planning, surgery, and a 3-year follow-up at regular intervals after the operation. The patient files comprise clinical recordings, photos, radiographs, and patient questionnaires. Cephalograms have been obtained 1 week before and 1 week, 2 and 6 months, and 1 and 3 years after surgery. The results presented here are based on observations from patients in whom the bony segments have been stabilized with rigid fixation only.

About 150 patients have been referred each year of whom 50 to $60 \%$ have undergone surgery. Pre-surgical orthodontic treatment lasts on average 18 months and post-surgical orthodontics 6 months (Dowling et al., 1999). The osteotomies that will be discussed in this chapter comprise one-piece LeFort I, bilateral sagittal split (BSSO) and extraoral vertical ramus osteotomies (EVRO), and genioplasty. Standardized protocols which have been followed over time have made it possible to establish homogenous subsamples of sufficient size for analyses of various aspects of treatment such as skeletal stability, sensory function, effect on airways and soft tissue profile, and patient satisfaction.

\section{Stability}

Skeletal relapse after orthognathic surgery may be due to biological factors like lack of neuromuscular adaptation and condylar resorption, as well as factors related to the surgical procedures. The extent of the relapse may be associated with the magnitude and direction of skeletal movements, the method of fixation, and the use of bone grafts. A hierarchy of 
stability based on initial anatomy and various surgical procedures has been proposed (Proffit et al., 1996). Relapse may be presented as the mean post-surgical change, or as the rate of subjects with a clinically significant relapse, usually defined as change of $2 \mathrm{~mm}$ or more. Another issue of importance is when the relapse occurs, and hence short- and longterm stability should be examined. Skeletal relapse may also to a varying extent impact on occlusal stability.

\subsection{Skeletal stability}

The results presented below is a compilation of findings from studies performed at the University of Oslo. The cephalometric variables have been recorded as $\mathrm{x}$ - and $\mathrm{y}$-coordinates (Fig. 1). The $x$-axis was constructed $7^{\circ}$ to the nasion-sella line. The most common osteotomies for management of Class II and III skeletal malocclusions will be addressed.

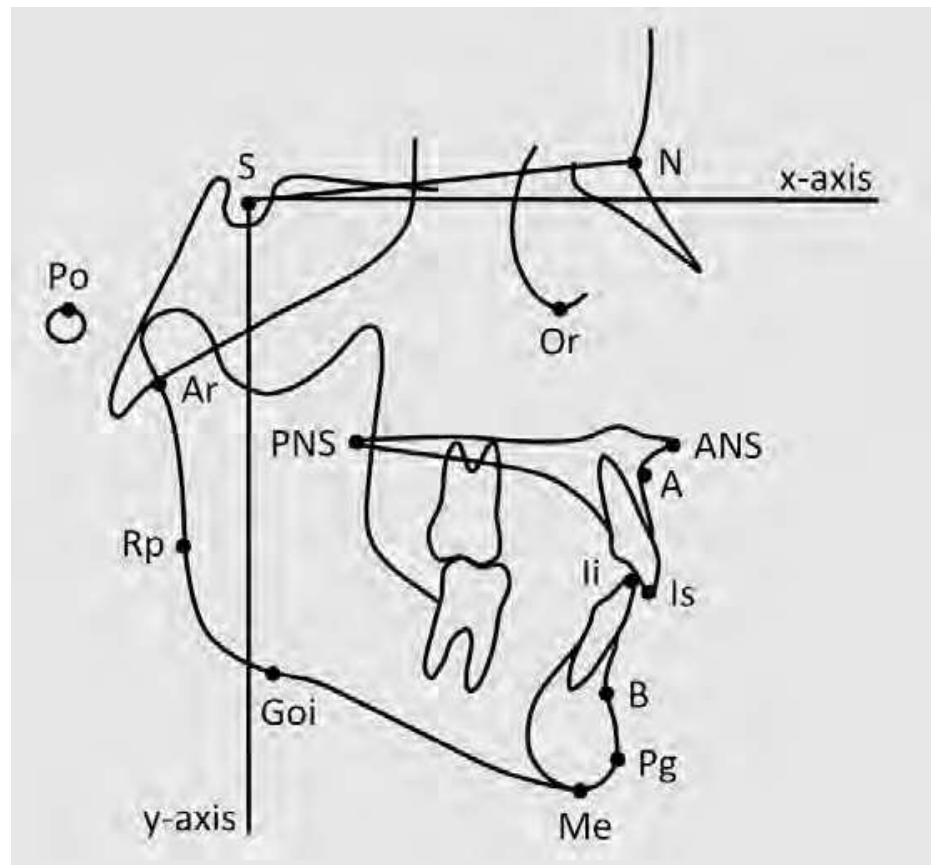

Fig. 1. Cephalometric landmarks used in analyses of stability

\subsubsection{Class III: mandibular setback}

The bilateral sagittal split osteotomy (BSSO) is a versatile and widely used approach for correction of mandibular prognathism. In a study of 80 (46 males, 34 females) consecutively operated patients (Mobarak et al., 2000a) this procedure appeared to be fairly stable. Three years post-surgery the mean relapse was $1.6 \mathrm{~mm}$ and represented $26 \%$ of the surgical setback at Pogonion $(\mathrm{Pg})(6.3 \mathrm{~mm})$. In $36 \%$ of the patients relapse was clinically significant $(\geq$ $2 \mathrm{~mm}$ ). Most of the relapse took place during the first 6 months after surgery (72\%) (Fig. 2). The magnitude of the setback was to some extent associated with the amount of horizontal relapse $(r=0.39, \mathrm{P}<0.01)$. Gender differences in relapse were small. 


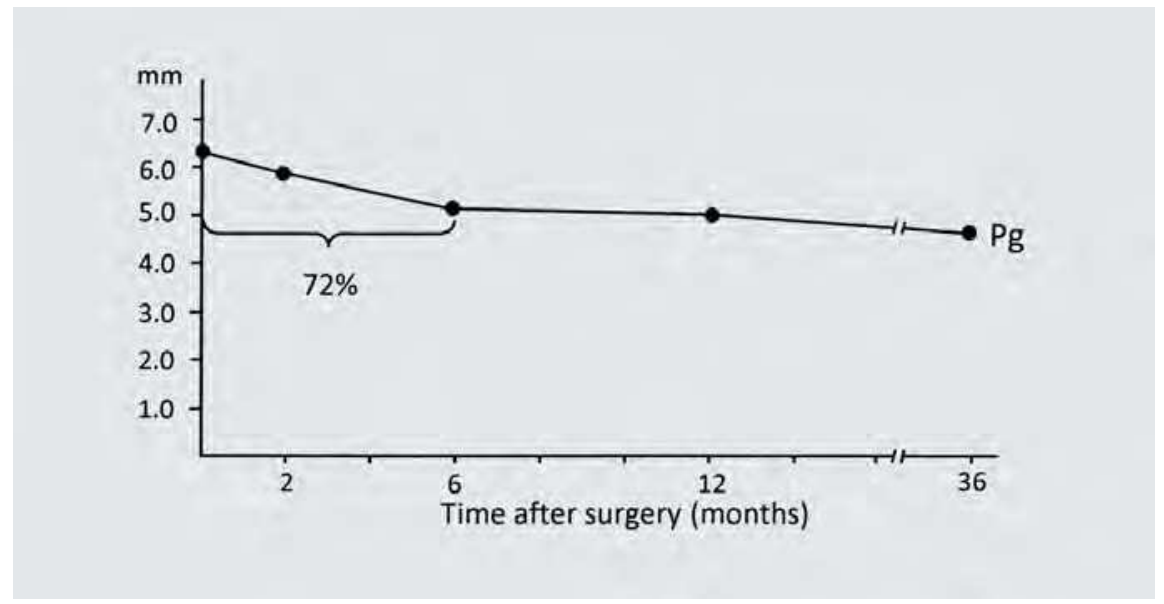

Fig. 2. Mean postsurgical horizontal change at $\mathrm{Pg}$ as a function of time in 80 mandibular setback (BSSO) patients.

An alternative approach to BSSO is the vertical ramus osteotomy (VRO). Traditionally the VRO has required intermaxillary fixation for 6-8 weeks. Since 1995, stable plate fixation has routinely been used with an extraoral incision by our team (Hoegevold et al., 2001) (Fig. 3). The main morphologic indication for applying the extraoral VRO (EVRO) has been a moderate setback without rotation. Another indication is related to reduced risk for sensory disturbances. In a 1-year follow-up study post-operative changes were mainly in the form of a small anterior relapse tendency of about $10 \%$ of the surgical setback. Mean relapse was 0.6 $\mathrm{mm}$ (SD $1.2 \mathrm{~mm}$ ). A relapse $\geq 2 \mathrm{~mm}$ was observed in $14 \%$ of the subjects (Mobarak et al., 2000b).
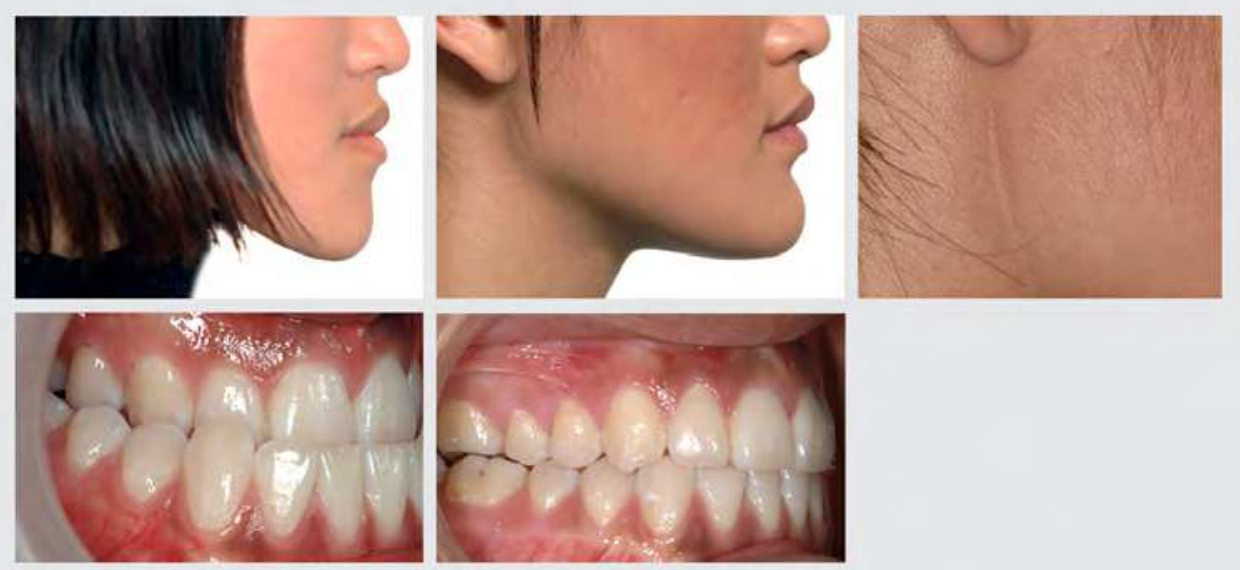

Fig. 3. Patient with mandibular prognathism before treatment and 3 years after EVRO. Facial scar after extraoral incision to the right. 


\subsubsection{Class III: maxillary advancement}

After the LeFort I osteotomy became common in the 1970-ies, this is an increasingly used alternative to correct Class III malocclusion. This approach allows treatment based on the diagnosis in cases where the discrepancy is caused by a retrognathic maxilla (Fig. 4). In addition to be associated with few unwanted side-effects like nerve injuries, a negative impact on the airways which may occur after mandibular setback, is avoided.

In a sample of 43 individuals having had maxillary advancement of $\geq 2 \mathrm{~mm}$ (mean advancement $5 \mathrm{~mm}$ ), the mean relapse was $0.9 \mathrm{~mm}(18 \%)$, and the relapse was clinically significant in $14 \%$ of the patients (Dowling et al., 2005). Almost all (89\%) of the relapse took place during the first 6 months. Regression analysis identified large advancements and downward movement of the anterior maxilla as risk factors for horizontal relapse.

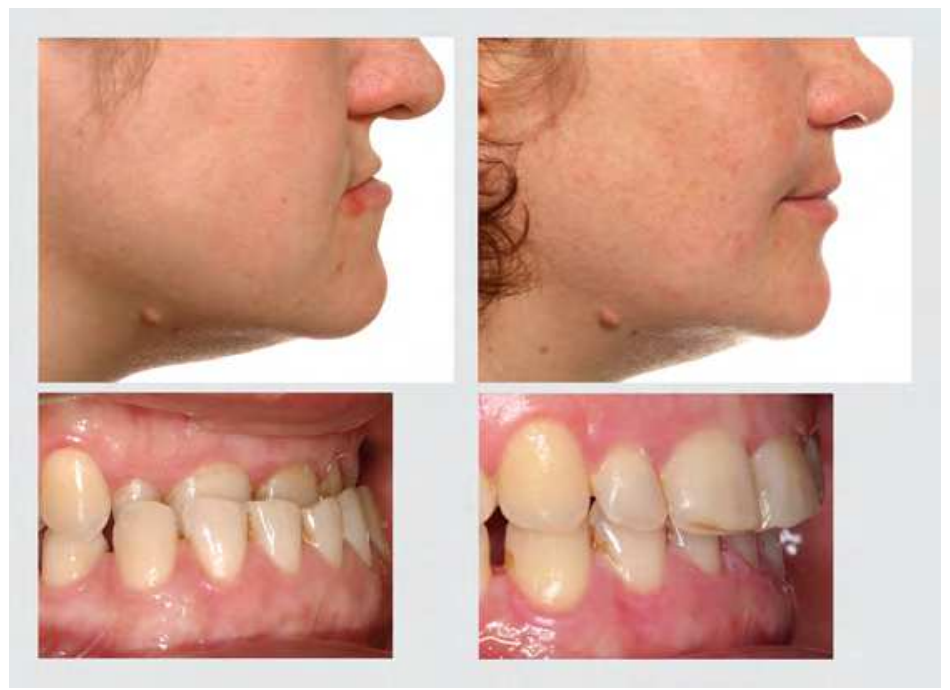

Fig. 4. Patient with retrognathic maxilla before and after maxillary advancement (one-piece LeFort I).

\subsubsection{Class III: bimaxillary surgery}

In patients with severe skeletal discrepancies single jaw surgery may not be possible or may have an unwanted effect on the patient's facial appearance. In later years, there has been a trend for increased use of a combination of mandibular setback and maxillary advancement. Severe skeletal Class III malocclusions are frequently associated with anterior open bite, which is more readily corrected with bimaxillary surgery and may also ensure optimal facial harmony (Fig. 5).

A study of stability comprised 81 patients (Jakobsone et al., 2011a) who pre-surgery had a mean negative overjet of $-7 \mathrm{~mm}$ (range -18.9 to $3.2 \mathrm{~mm}$ ) and a negative overbite of -1.8 (range -9.7 to $6.4 \mathrm{~mm}$ ). Skeletal stability assessed 3 years after surgery varied depending on the direction and amount of the surgical repositioning. Maxillary advancement was stable, whereas a significant mean relapse was observed after mandibular setback (Fig. 6). About half of the 62 subjects with a setback of $2 \mathrm{~mm}$ or more, had a clinically significant relapse. Most of the skeletal relapse occurred during the first 6 months after surgery. Regression 
analysis showed that stability was increased when the setback was small and the posterior maxilla was impacted.
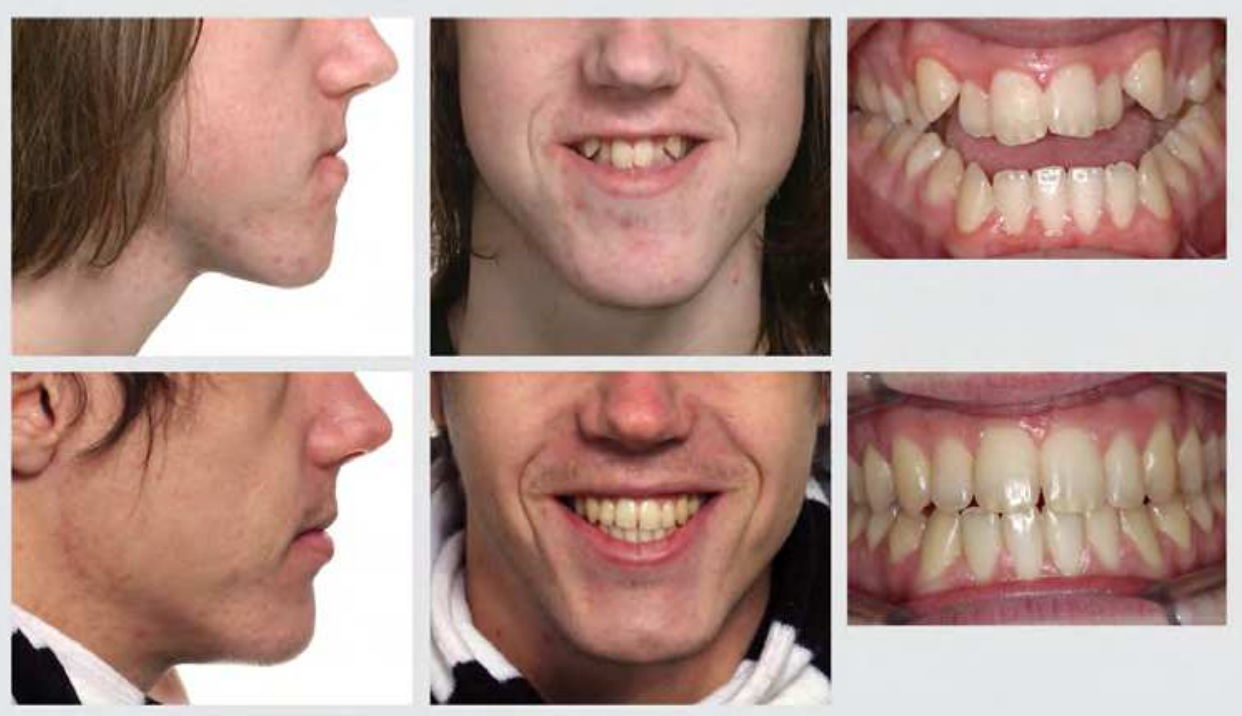

Fig. 5. Patient with severe Class III malocclusion and open bite corrected with one-piece LeFort I and BSSO (before treatment and 3 years after surgery).

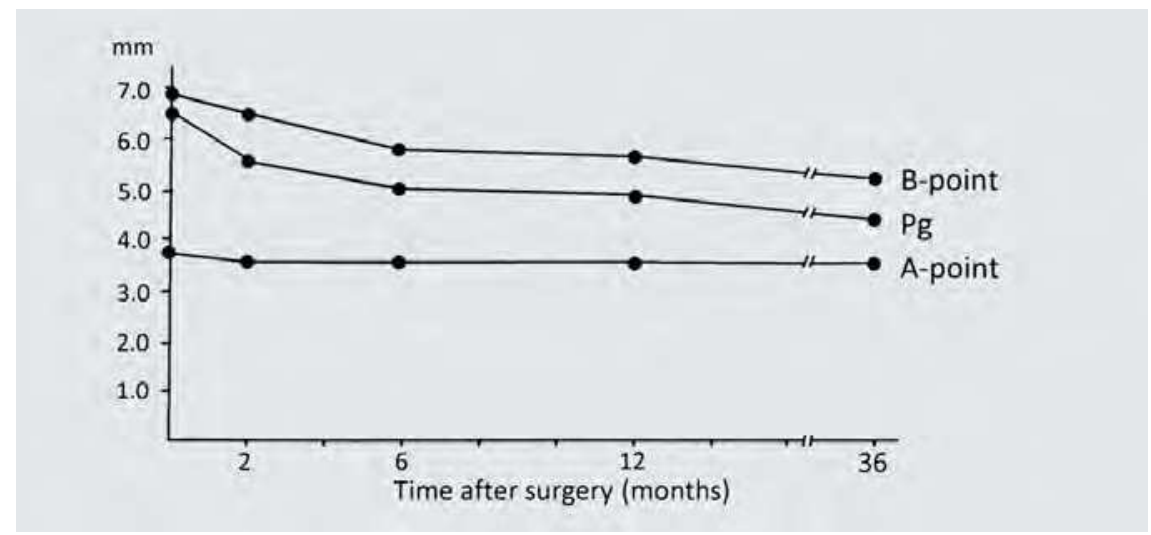

Fig. 6. Mean horizontal changes at various cephalometric landmarks as a function of time in 81 Class III patients having bimaxillary surgery (BSSO and one-piece LeFort I).

\subsubsection{Class II: mandibular advancement}

The BSSO is the most frequently used osteotomy for management of mandibular retrognatism. High-angle and low-angle Class II cases represent two distinct entities, with different facial patterns, treatment goals, and clinical challenges. 
A study of stability analysed these two categories separately in 61 consecutive cases (Mobarak et al., 2001a). High- $(n=20)$ and low-angle $(n=20)$ patients had different patterns of surgical and post-operative skeletal changes. High-angle cases were associated with greater horizontal relapse. Relapse in the low-angle cases occurred early in the postoperative period, whereas in the high-angle cases, relapse was a more continuous process with a significant proportion occurring later in the follow-up period (Fig. 7). Increasing the anterior facial height (low-angle) was a relatively stable procedure, with on average $70 \%$ of the improvement remaining after 3 years.

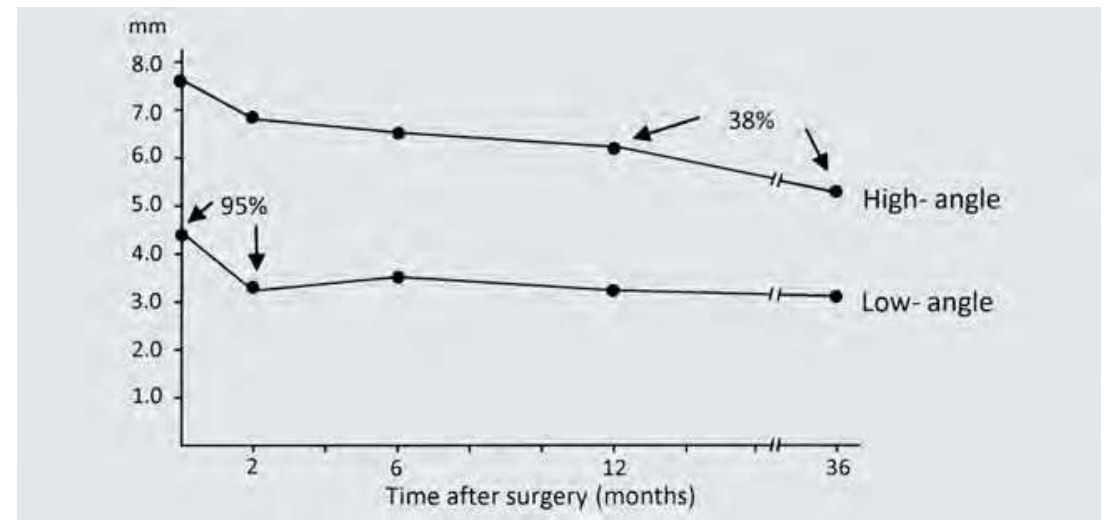

Fig. 7. Mean horizontal changes at Pg in low- and high-angle cases as a function of time. Mean surgical advancement appears from the vertical axis.

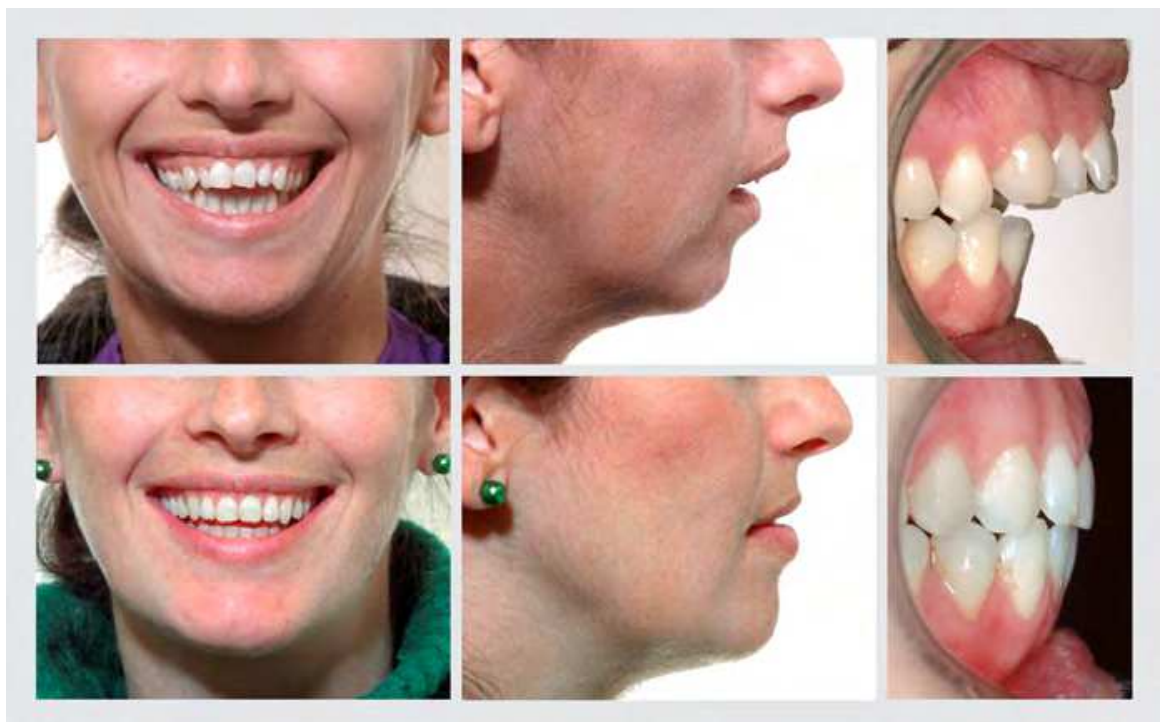

Fig. 8. Patient with severe Class II with open bite and high-angle facial pattern before treatment and 3 years after surgery with BSSO and one-piece LeFort I. 


\subsubsection{Class II: bimaxillary surgery}

Our studies of stability after bimaxillary surgery to correct skeletal Class II malocclusion have focused on subjects with a high-angle facial pattern as this group represents the greatest challenge. In a study of 31 patients (ML/NSL $>38^{\circ}$ ) the stability of maxillary impaction and mandibular advancement varied considerably (Winter et al., 2010). Stable results (relapse $<2 \mathrm{~mm}$ ) after maxillary impaction were observed in $77 \%$ of the subjects, whereas mandibular advancements were stable in only $42 \%$. Despite the risk for relapse, some patients showed excellent results after 3 years (Fig. 8).

\subsubsection{Class II: advancement genioplasty}

Genioplasty allows 3-dimensional control of chin position, resulting in significant improvement of facial aesthetics whether performed separately or combined with other osteotomies. Of the actual corrections of the chin, advancement genioplasty to improve a receding chin is probably the most common.

Our study of stability after advancement genioplasty included 21 subjects who had no additional osteotomies (Shaughnessy et al., 2006) (Fig. 9). Mean advancement was $8.4 \mathrm{~mm}$. The results 3 years after surgery showed that this was a stable procedure with a mean relapse of only $8 \%$ of the advancement. Some of the post-surgical change could be ascribed to remodelling in the area rather than instability of the segment.

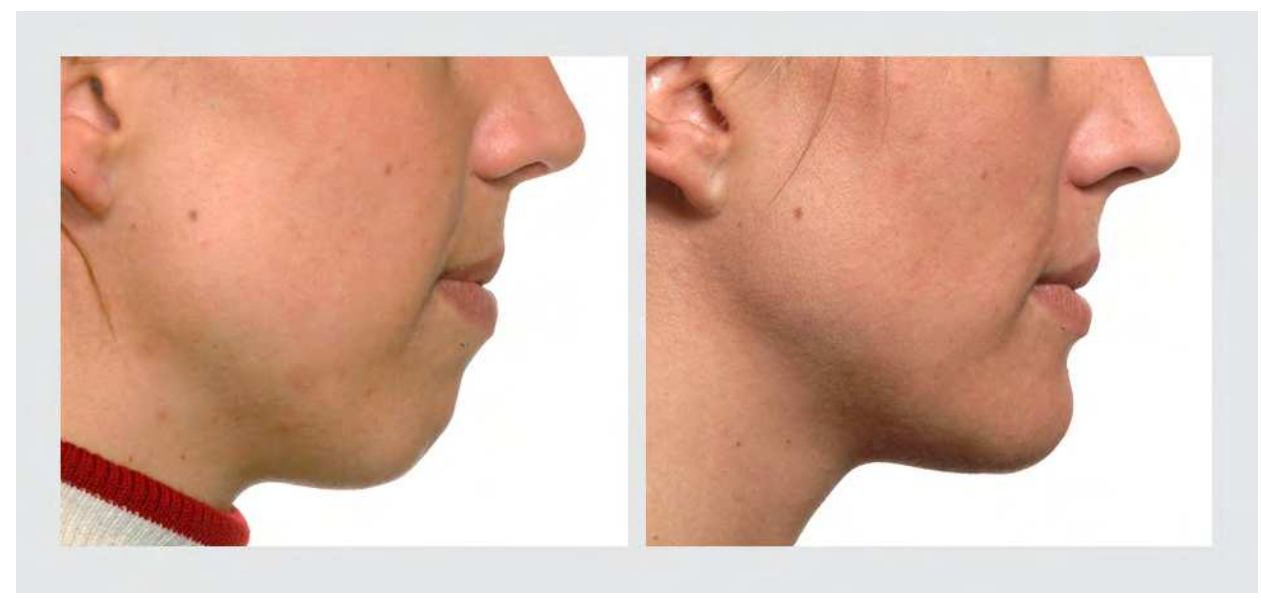

Fig. 9. Advancement genioplasty patient pre-treatment (left) and 3 years after surgery (right).

\subsubsection{Open bite correction by isolated maxillary surgery}

Open bite occurs both in Class I, II, and III malocclusions. When the sagittal discrepancy is moderate, the occlusion can usually be corrected by LeFort I impaction as the only procedure (Fig. 10). In a study of 40 consecutively operated patients (Espeland et al., 2008a) it was observed that impaction of posterior maxilla $(\geq 2 \mathrm{~mm}$ ) relapsed by one third. Inferior movement of the anterior maxilla relapsed about two thirds. Most of the relapse occurred during the first 6 months after surgery. 


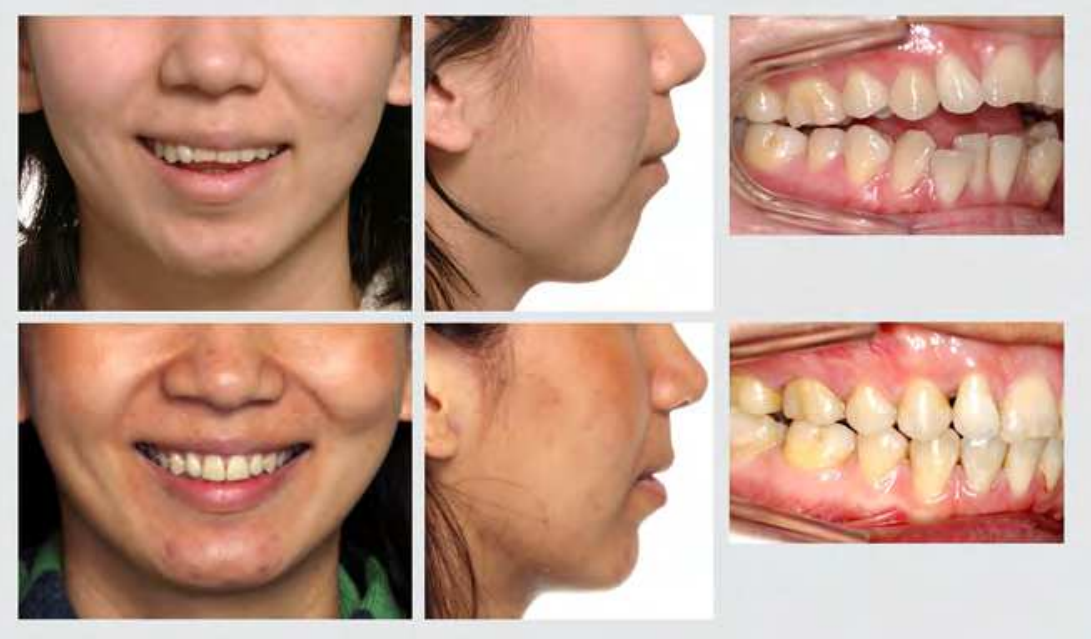

Fig. 10. Patient with open bite before treatment and after one-piece LeFort I with impaction of posterior maxilla.

\subsubsection{Summary - skeletal stability}

Fig. 11 summarizes frequencies of stable results (relapse $<2 \mathrm{~mm}$ ) after various one-jaw osteotomies. The most stable results were observed after advancement of the maxilla, setback of the mandible (EVRO), and advancement of the chin. The least stable procedures were advancement of the mandible in patients with high-angle facial pattern and downward movement of the maxilla. In the literature a number of factors have been proposed which may explain skeletal relapse. For Class III anomalies early relapse has been associated with clockwise rotation of the proximal segment during BSSO-surgery (Proffit et al., 1996). In our study (Mobarak et al., 2000a), however, this did not seem to be responsible for marked relapse. Late relapse has often been ascribed to late mandibular growth which our findings also indicated. For Class II corrections by BSSO advancement, early relapse has been suggested to be due to suboptimal positioning of the condyle, whereas condylar resorption might be responsible for relapse occurring later. Risk factors for condylar resorption have been addressed in the literature, for example condylar morphology and bone quality (Hoppenreijs et al., 1999).

\subsection{Occlusal stability}

Despite some skeletal relapse after most surgical corrections, the anterior occlusion is generally stable. In the studies addressing stability referred to above, the incisor relationship was also examined. Below is a short summary of the main findings.

After Class III correction by one-jaw surgery, both with setback of the mandible (Mobarak et al., 2000a) and advancement of the maxilla (Dowling et al., 2005), all patients examined had a positive overjet 3 years after the operation. Bimaxillary surgery resulted in positive overjet in 79 of 81 patients (Jakobsone et al., 2011a). Relapse of open bite was observed in 8 subjects, and in 5 of these, the negative overbite was less than $1 \mathrm{~mm}$. 


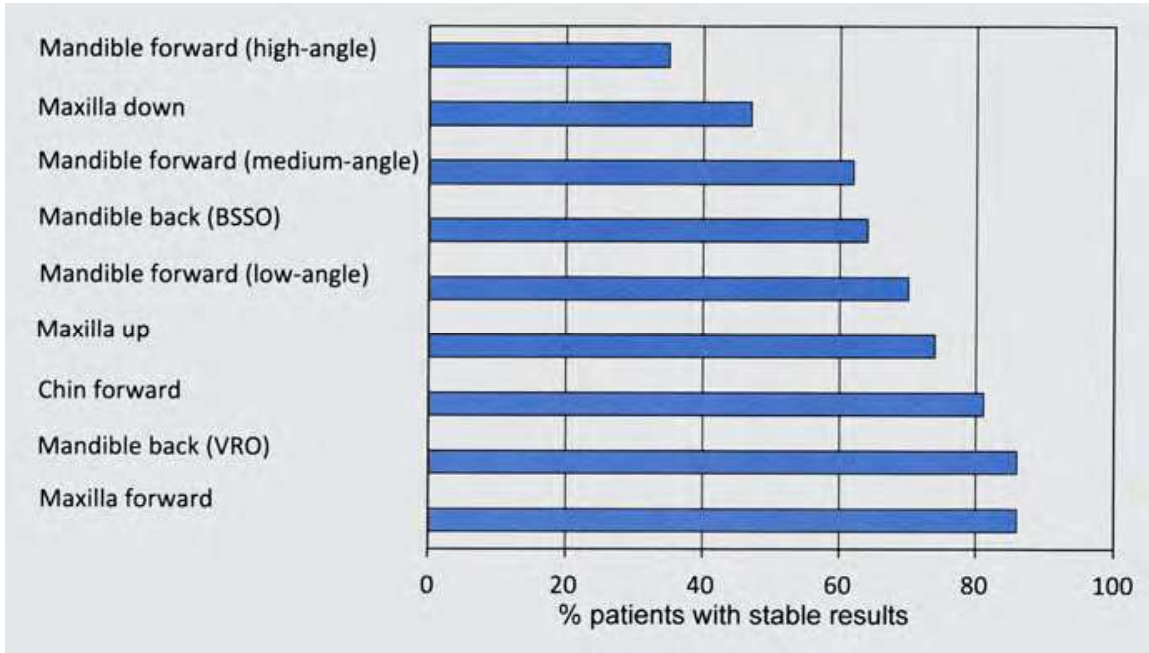

Fig. 11. Diagrammatic representation of stability after various one-jaw surgical procedures. Bars represent frequency of patients with relapse less than $2 \mathrm{~mm} 3$ years after surgery.

After Class II correction with mandibular advancement, the difference in skeletal stability between patients with low- and high-angle facial pattern was reflected in the stability of the occlusion. After 3 years $85 \%$ of the low-angle patients had overjet less than $4 \mathrm{~mm}$, whereas the corresponding figure for the high-angle subjects was $60 \%$. In the group of 41 high-angle patients treated with bimaxillary surgery, one third of those having overjet $>6 \mathrm{~mm}$ before surgery, still had an overjet $>6 \mathrm{~mm}$ after 3 years.

Of 40 open-bite patients treated by isolated LeFort I impaction, $88 \%$ had positive overbite 3 years post-surgery (Espeland et al., 2008a). In all the remaining patients, the negative overbite was less than $1 \mathrm{~mm}$. The skeletal relapse was counteracted by dentoalveolar compensation, which contributed to approximately $50 \%$ of the correction of the overbite.

For all categories of malocclusion, the skeletal relapse generally took place during the first 6 months. A negative effect on the occlusion was avoided for most patients by dentoalveolar compensation, which underlines the importance of post-surgical monitoring and orthodontic management if signs of relapse become apparent.

\section{Soft tissue response}

Software for prediction of the soft tissue response has become an integral part of treatment planning aiming to provide a realistic estimate of the outcome of surgery. Ratios (or percentages) for soft to hard tissue changes have focused in particular on nose, lips, mentolabial fold, and chin. It is important that the data which serve to generate software prediction programs are valid. Changes in sagittal and vertical dimensions as well as lip thickness have been addressed in studies at our department.

\subsection{Class III: mandibular setback}

The soft tissue response for the lower lip, mentolabial fold and soft tissue chin to the underlying hard tissues was about 1:1. Some effect was also seen for the upper lip (Fig. 12). 
The main effect of mandibular setback on the soft tissue profile included an increase in facial convexity, straightening and lengthening of the upper lip with a concomitant increase in nasolabial angle, and deepening of the mentolabial fold (Mobarak et al., 2001b).

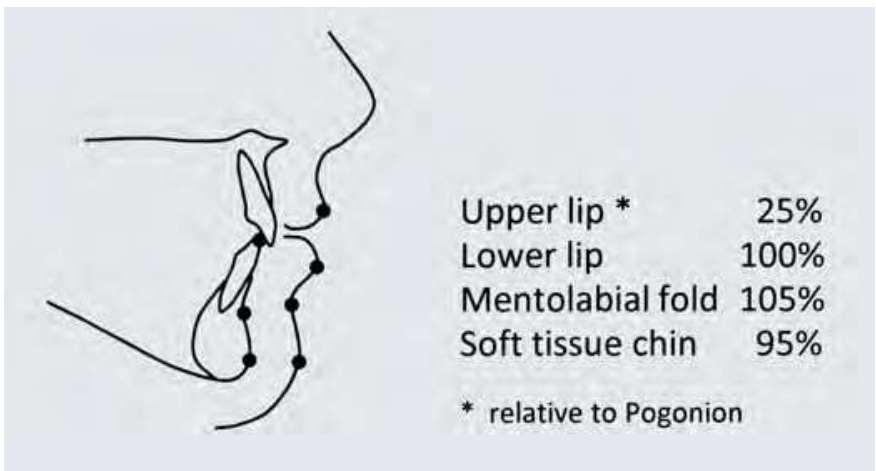

Fig. 12. Relationship between soft and hard tissue horizontal changes after mandibular setback in 80 patients (BSSO).

\subsection{Class III: bimaxillar surgery}

To quantify the relative soft tissue response to the skeletal changes, a sample of 80 patients were divided in 3 subgroups according to pre-operative characteristics: 1) open bite, 2) positive overbite and the upper lip resting on upper incisors, and 3) positive overbite and the upper lip resting on lower incisors (lip block) (Jakobsone et al., 2011b).

In the first two groups, there were strong correlations between the horizontal movement of upper incisors and upper lip $(r=0.77$ and 0.85 , respectively). The upper lip followed the maxilla with a ratio of $0.5: 1$. When the upper lip rested on lower incisors before surgery, the association between maxillary repositioning and upper lip changes were weak. In all groups a strong association between horizontal soft and hard tissue changes of lower lip and chin was observed. The vertical position of the tip of the nose was affected by both the vertical and horizontal repositioning of the maxilla. Several factors influencing the soft tissue response were identified. Software prediction programs should preferably take into account different pre-surgical characteristics.

\subsection{Class II: mandibular advancement}

The ratio for the soft to hard tissue response after mandibular advancement was about 1:1 for the chin and 0.6:1 for the lower lip. For the mentolabial fold, the ratio was on average 0.9:1, but varied somewhat according to vertical facial pattern (Mobarak et al., 2001c). Following mandibular advancement the facial profile became straighter. The mentolabial fold became more shallow, especially in low-angle subjects who also had an increase in anterior facial height.

\subsection{Class II: advancement genioplasty}

In our study of soft tissue response to advancement of the chin as the only surgical procedure, the results showed that the ratio for soft to hard tissue movement was 0.9:1 (Shaughnessy et al., 2006). The mentolabial depth increased as a result of treatment (Fig. 9). 


\section{Effect on upper airways}

In addition to the changes in masticatory function and facial harmony, repositioning of the jaws may also impact on airway morphology. Mandibular advancement and setback osteotomies have been reported to influence the position of the hyoid bone, and consequently tongue position, pharyngeal airway morphology, and head flexion (Achilleos et al., 2000a,b). Studies have also shown that in adults, there is on average a reduction in the sagittal dimension of the minimal pharyngeal airway space with increasing age (Kollias \& Krogstad, 1999). Over the last two decades the capacity of maxillo-mandibular osteotomies to induce or resolve obstructive sleep apnoea (OSA) has received increased attention. A challenge in the planning of orthognathic surgery is to balance concerns related to facial aesthetics and airway changes.

A recent study of bimaxillary correction of Class III malocclusion examined whether maxillary advancement and/or impaction had the potential to compensate for the negative effect of mandibular setback on airways (Jakobsone et al., 2011c).

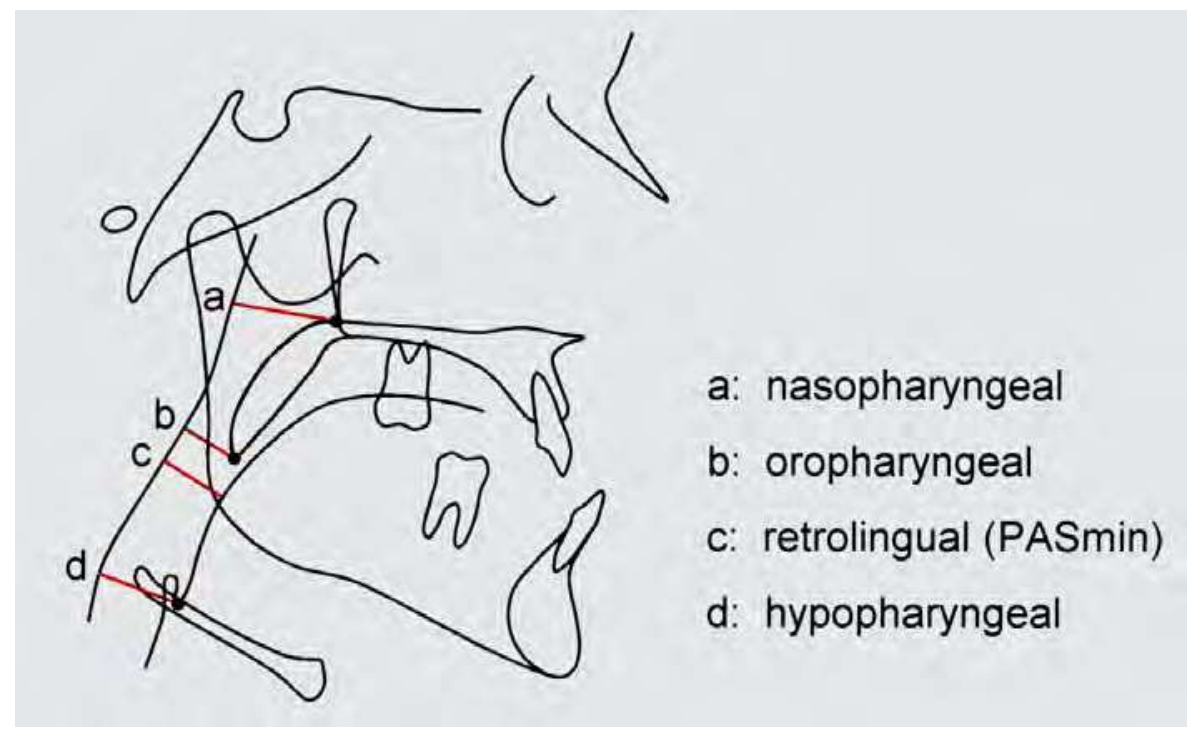

Fig. 13. The 4 levels in the upper airways which were cephalometrically examined.

Sagittal dimensions of the pharynx were measured on 4 different levels (Fig. 13) in 4 subgroups. The long-term change ( 3 years) at the various levels related to whether the maxilla was advanced and/or impacted or not, appears from Fig. 14. Advancement of the maxilla resulted in an increase of $15-20 \%$ at the nasopharyngeal level. At the hypopharyngeal level, advancement of the maxilla did to some extent compensate for the negative effect of mandibular setback. A decrease of $5-10 \%$ was observed at the oropharyngeal and retrolingual (PASmin) levels. 


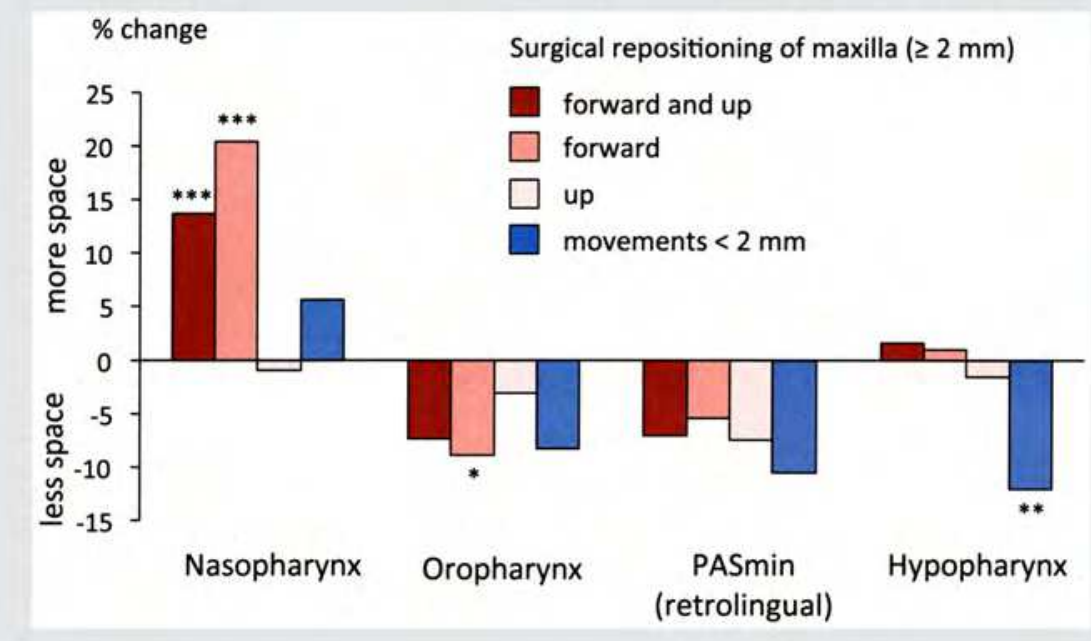

Fig. 14. Change (\%) in sagittal dimension of the upper airways related to varying maxillary repositionings in subjects undergoing bimaxillary surgery for correction of Class III malocclusion.

\section{Sensory function}

Impairment of sensory function is the most common long-term side effect after orthognathic surgery, especially following sagittal split osteotomies (Westermark et al., 1999). In our sample of 381 patients operated with bilateral sagittal split osteotomy (BSSO), 47.8\% reported altered sensory function 3 years after the operation (Table 1).

\begin{tabular}{cc}
\hline Patient's report & $\%$ patients \\
\hline Normal /almost normal & 52.2 \\
Reduced & 40.4 \\
Increased & 6.3 \\
Complete loss & 1.0 \\
\hline
\end{tabular}

Table 1. Patients' reports of sensation in the lower lip and chin 3 years after bilateral sagittal split osteotomy.

Among patients with impaired sensation $(n=181), 40.9 \%$ indicated that the impairment was of concern to them because it affected their daily life. A mild distress was reported by $28.2 \%$, $8.3 \%$ reported a moderate distress, and $4.4 \%$ said the situation caused severe distress. The age at the time of surgery was significantly associated with self-reported alterations in sensory function $(P<0.001)$. Distress due to impaired sensation also increased with age $(P=$ 0.024) (Fig. 15). 


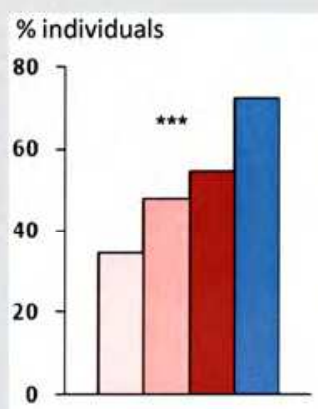

A

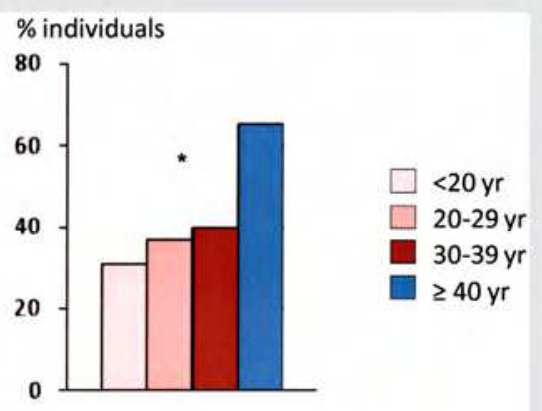

B

Fig. 15. A: Relative frequency of individuals reporting altered sensory function according to age among 381 subjects operated with BSSO. B: Relative frequency of individuals reporting varying levels of distress (mild, moderate, and severe combined) according to age among 181 who reported altered sensation. ${ }^{*} \mathrm{P}<0.05,{ }^{* * *} \mathrm{P}<0.001$.

\section{Patients' satisfaction with treatment results}

Orthognathic surgery may have an impact on quality of life (Cunningham et al., 2002). At a clinical review 3 years after surgery, patients monitored by our team fill in a questionnaire addressing their opinions of the treatment result in terms of improvement in dental and facial appearance, chewing ability, speech, impact on social life, satisfaction with overall result, and whether they would re-elect surgery with their present experience (Espeland et al., 2008b). Findings among 705 consecutively operated patients appear from Tables 2-4. Totally $90.6 \%$ reported that they were satisfied with the overall treatment result, and $88.5 \%$ indicated that they would have re-elected surgery based on their present experiences. Of those expressing dissatisfaction, $47.0 \%$ stated that they would have made the same decision.

\begin{tabular}{ccccc}
\hline & Very satisfied & Satisfied & $\begin{array}{c}\text { Somewhat } \\
\text { dissatisfied }\end{array}$ & $\begin{array}{c}\text { Very } \\
\text { dissatisfied }\end{array}$ \\
\hline Females $(\mathrm{n}=399)$ & 56.6 & 31.1 & 10.5 & 1.8 \\
Males $(\mathrm{n}=306)$ & 64,4 & 30.1 & 4.9 & 0.7 \\
Total $(\mathrm{n}=705)$ & 60.0 & 30.6 & 8.1 & 1.3 \\
\hline
\end{tabular}

Table 2. Patients' answers to a question about satisfaction with the treatment result (\%). Significant difference between genders $(P=0.017)$.

\begin{tabular}{ccc}
\hline & Satisfied & $\begin{array}{c}\text { Dissatisfied } \\
(\%)\end{array}$ \\
\hline Skeletal Class I $(\mathrm{n}=97)$ & $(\%)$ & 6.2 \\
Skeletal Class II $(\mathrm{n}=214)$ & 93.8 & 17.8 \\
Skeletal Class III $(\mathrm{n}=394)$ & 82.2 & 5.6 \\
\hline
\end{tabular}

Table 3. Patients' reports on satisfaction/dissatisfaction related to skeletal malocclusion. Significant difference between categories $(P<0.001)$. 


\begin{tabular}{|c|c|c|}
\hline & $\begin{array}{c}\text { Satisfied } \\
(\%)\end{array}$ & $\begin{array}{c}\text { Dissatisfied } \\
(\%)\end{array}$ \\
\hline Mandibular setback $(\mathrm{n}=226)$ & 96.0 & 4.0 \\
\hline Mandibular setback and LeFort I $(n=119)$ & 94.1 & 5.9 \\
\hline Mandibular advancement $(n=130)$ & 83.1 & 16.9 \\
\hline Mandibular advancement and LeFort I $(n=30)$ & 76.7 & 23.3 \\
\hline Maxillary surgery (LeFort I) $(\mathrm{n}=124)$ & 88.7 & 11.3 \\
\hline Other procedures $(\mathrm{n}=76)$ & 90.8 & 9.2 \\
\hline
\end{tabular}

Table 3. Patients' reports on satisfaction/dissatisfaction related to surgical approach. Significant difference between approaches $(P<0.001)$.

Relatively more males than females were satisfied, and correction of Class III malocclusion was associated with increased frequency of satisfied patients. The patients' stated reasons for dissatisfaction were allocated to the following categories: impaired nerve function $(n=16)$, relapse $(n=18)$, appearance $(n=17)$, TMJ problems $(n=8)$, occlusal function $(6)$, and other reasons $(\mathrm{n}=11)$.

\section{Concluding remarks}

Orthognatic surgery may on the basis of systematic monitoring of outcomes according to our established protocols be regarded as a treatment modality that predictably leads to the correction of severe occlusal anomalies. Skeletal corrections are also generally stable and even if some relapse may occur, the occlusion is usually not affected due to orthodontic compensation during the first post-surgical months. Most patients are also satisfied with the result. Improvement in facial soft-tissue profile and the effect on upper airways are less predictable. Class II malocclusions represents a greater challenge compared to other anomalies, especially in patients with high-angle facial pattern.

\section{Acknowledgment}

The authors are greatly indebted to Håkon Størmer for excellent support in preparation of the illustrations.

\section{References}

Achilleos, S., Krogstad, O. \& Lyberg T. (1979). Surgical mandibular advancement and changes in uvuloglossopharyngeal morphology and head posture : a short- and long-term cephalometric study in males. European Journal of Orthodontics, Vol.22, No.4, (August 2000a), pp. 367-381, ISSN 0141-5387

Achilleos, S., Krogstad, O. \& Lyberg T. (1979). Surgical mandibular setback and changes in uvuloglossopharyngeal morphology and head posture: a short- and long-term cephalometric study in males. European Journal of Orthodontics, Vol.22, No.4, (August 2000b), pp. 383-394, ISSN 0141-5387

Cunningham S.J., Garratt, A.M. \& Hunt, M.P. (1973). Development of a condition-specific quality of life measure for patients with dentofacial deformity: II. Validity and responsiveness testing. Community Dentistry and Oral Epidemiology, Vol.30, No.2, (April 2002), pp. 81-90, ISSN 0301-5661 
Dowling, P.A., Espeland, L., Krogstad, O., Stenvik, A. \& Kelly, A. (1986). Duration of orthodontic treatment involving orthognathic surgery. The International Journal of Adult Orthodontics and Orthognathic Surgery, Vol. 14, No.2, (Summer 1999), pp. 146152, ISSN 0742-1931

Dowling, P.A., Espeland, L., Mobarak, K.A. \& Hogevold, H.E. (1986). LeFort I maxillary advancement: 3-year stability and risk factors for relapse. American Journal of Orthodontics and Dentofacial Orthopedics, Vol.128, No.5 (November 2005), pp. 560567, ISSN 0889-5406

Espeland, L., Dowling, P.A., Mobarak, K.A. \& Stenvik, A. (1986). Three-year stability of open-bite correction by 1-piece maxillary osteotomy. American Journal of Orthodontics and Dentofacial Orthopedics, Vol.134, No.1, (July 2008a), pp. 60-66, ISSN 0889-5406

Espeland, L., Høgevold H.E. \& Stenvik, A. (1979). A 3-year patient-centred follow-up of 516 consecutively treated orthognathic surgery patients. European Journal of Orthodontics, Vol.30, No.1, (February 2008b), pp. 24-30, ISSN 0141-5387

Hoppenreijs, T.J.M., Stoelinga, P.J.W., Grace, K.L. \& Robben, C.M.G. (1986). Long-term evaluation of patients with progressive condylar resorption following orthognathic surgery. International Journal of Oral and Maxillofacial Surgery, Vol.28, No.6, (December 1999), pp. 411-418, ISSN 0901-5027

Høgevold, H.E., Mobarak, K.A., Espeland, L., Krogstad, O. \& Skjelbred, P. (1987). Plate fixation of extra-oral subcondylar ramus osteotomy for correction of mandibular prognathism: clinical aspects and short term stability. Journal of Cranio-maxillo-facial Surgery, Vol.29, No.4, (August 2001), pp. 205-211, ISSN 1010-5182

Jakobsone, G., Stenvik A., Sandvik, L. \& Espeland, L. (1986). Three-year follow-up of bimaxillary surgery to correct skeletal Class III malocclusion: stability and risk factors for relapse. American Journal of Orthodontics and Dentofacial Orthopedics, Vol.139, No.1, (January 2011a), pp. 80-89, ISSN 0889-5406

Jakobsone, G., Stenvik, A. \& Espeland, L. Predicting the soft tissue profile changes after bimaxillary operations for Class III correction, Proceedings of EOS 2011 87th Congress of the European Orthodontic Society, Istanbul, Turkey, June 19-23, 2011b

Jakobsone, G., Stenvik, A. \& Espeland, L. (1986). The effect of maxillary advancement and impaction on the upper airway after bimaxillary surgery to correct Class III malocclusion. American Journal of Orthodontics and Dentofacial Orthopedics, (April 2011c) (in press)

Kollias, I. \& Krogstad, O. (1979). Adult craniocervical and pharyngeal changes - a longitudinal cephalometric study between 22 and 42 years of age. Part II: morphological uvulo-glossopharyngeal changes. European Journal of Orthodontics, Vol.21, No.4, (August 1999), pp. 345-355, ISSN 0141-5387

Mobarak, K.A., Krogstad, O., Espeland, L. \& Lyberg, T. (1986). Long-term stability of mandibular setback surgery: a follow-up of 80 bilateral sagittal split osteotomy patients. The International Journal of Adult Orthodontics and Orthognathic Surgery, Vol 15, No.2, (Summer 2000a), pp. 83-95, ISSN 0742-1931

Mobarak, K.A., Krogstad, O., Espeland, L. \& Lyberg, T. (1986). Stability of extraoral vertical ramus osteotomy: plate fixation versus maxillomandibular/skeletal suspension wire fixation. The International Journal of Adult Orthodontics and Orthognathic Surgery, Vol.15, No.2, (Summer 2000b), pp. 97-113, ISSN 0742-1931 
Mobarak, K.A., Espeland, L., Krogstad, O. \& Lyberg, T. (1986). Mandibular advancement surgery in high-angle and low-angle Class II patients: different long-term skeletal responses. American Journal of Orthodontics and Dentofacial Orthopedics, Vol.119, No.4, (April 2001a), pp. 368-381, ISSN 0889-5406

Mobarak, K.A., Krogstad, O., Espeland, L. \& Lyberg, T. (1931). Factors influencing the predictability of soft tissue profile changes following mandibular setback surgery. The Angle Orthodontist, Vol.71, No.3, (June 2001b), pp. 216-227, ISSN 0003-3219

Mobarak, K.A., Espeland, L., Krogstad, O. \& Lyberg, T. (1986). Soft tissue profile changes following mandibular advancement surgery: predictability and long-term outcome. American Journal of Orthodontics and Dentofacial Orthopedics, Vol.119, No.4, (April 2001c), pp. 353-367, ISSN 0889-5406

Proffit, W.R., Turvey, T.A. \& Phillips, C. (1986). Orthognathic surgery: A hierarchy of stability. The International Journal of Adult Orthodontics and Orthognathic Surgery, Vol.11, No.3 (1996), pp. 191-204, ISSN 0742-1931

Shaughnessy, S., Mobarak, K.A., Høgevold, H.E. \& Espeland L. (1986). Long-term skeletal and soft-tissue responses after advancement genioplasty. American Journal of Orthodontics and Dentofacial Orthopedics, Vol.130, No.1. (July 2006), pp. 8-17, ISSN 0889-5406

Westermark, A., Bystedt, H. \& von Konow, L. (1986). Patients' evaluation of the final result of sagittal split osteotomy: is it influenced by impaired sensitivity of the lower lip and chin? The International Journal of Adult Orthodontics and Orthognathic Surgery, Vol.14, No.2, (Summer 1999), pp. 135-139, ISSN 0742-1931

Winter, B.U., Stenvik, A. \& Espeland, L. Bimaxillary orthognathic surgery of high-angle skeletal Class II malocclusions - stability after 3 years, Proceedings of WFO $20107^{\text {th }}$ International Orthodontic Congress, Sydney, Australia, Abstract 1505, February 6-9, 2010 


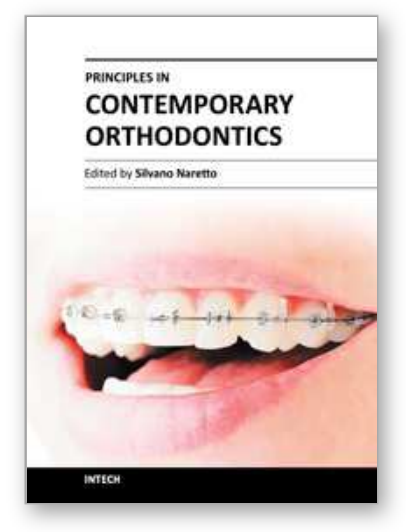

\author{
Principles in Contemporary Orthodontics \\ Edited by Dr. Silvano Naretto
}

ISBN 978-953-307-687-4

Hard cover, 584 pages

Publisher InTech

Published online 25, November, 2011

Published in print edition November, 2011

Orthodontics is a fast developing science as well as the field of medicine in general. The attempt of this book is to propose new possibilities and new ways of thinking about Orthodontics beside the ones presented in established and outstanding publications available elsewhere. Some of the presented chapters transmit basic information, other clinical experiences and further offer even a window to the future. In the hands of the reader this book could provide an useful tool for the exploration of the application of information, knowledge and belief to some orthodontic topics and questions.

\title{
How to reference
}

In order to correctly reference this scholarly work, feel free to copy and paste the following:

Lisen Espeland and Arild Stenvik (2011). Long-Term Outcome of Orthognathic Surgery, Principles in Contemporary Orthodontics, Dr. Silvano Naretto (Ed.), ISBN: 978-953-307-687-4, InTech, Available from: http://www.intechopen.com/books/principles-in-contemporary-orthodontics/long-term-outcome-of-orthognathicsurgery

\section{INTECH}

open science | open minds

\section{InTech Europe}

University Campus STeP Ri

Slavka Krautzeka 83/A

51000 Rijeka, Croatia

Phone: +385 (51) 770447

Fax: +385 (51) 686166

www.intechopen.com

\section{InTech China}

Unit 405, Office Block, Hotel Equatorial Shanghai

No.65, Yan An Road (West), Shanghai, 200040, China

中国上海市延安西路65号上海国际贵都大饭店办公楼405单元

Phone: +86-21-62489820

Fax: +86-21-62489821 
(C) 2011 The Author(s). Licensee IntechOpen. This is an open access article distributed under the terms of the Creative Commons Attribution 3.0 License, which permits unrestricted use, distribution, and reproduction in any medium, provided the original work is properly cited. 